\title{
Does measurement of serum dexamethasone increase diagnostic accuracy of the overnight dexamethasone- suppression test?
}

Ueland GÅ, Methlie P, Thordarson H, Løvås K, Kellmann R, Mellgren G, Kelp O, Husebye ES

Department of Clinical Science, University of Bergen, Norway; Dept. of Endocrinology and The Hormone laboratory, Haukeland University Hospital, Bergen, Norway; Dept. of Endocrinology, Akershus University Hospital

\section{Background}

The 1-mg overnight dexamethasone-suppression test (DST) is commonly used to screen for hypercortisolism. Sensitivity is high (95\%), but specificity is lower $(80 \%)$, leading to false positive results. Identifying individuals with abnormal dexamethasone absorption or metabolism could enhance diagnostic accuracy

\section{Aims}

- Define the concentration of s-Dexamethasoen (s-DXT) after DST, sufficient to suppress cortisol $<50 \mathrm{nmol} / \mathrm{L}$

- Estimate the proportion of positive DSTs explained by insufficient levels of sDXT

- Evaluate the reproducibility of s-Cortisol with repeated DSTs

\section{Materials and methods}

Table 1: Patient characteristics

\begin{tabular}{|l|c|c|c|c|}
\hline & Incidentalomas & Suspected CS & $\begin{array}{l}\text { Healthy } \\
\text { controls }\end{array}$ & \multicolumn{1}{|l|}{ Total } \\
\hline $\begin{array}{l}\text { Patients, N } \\
\begin{array}{l}\text { Women } \\
\text { N (\%) }\end{array}\end{array}$ & \multicolumn{1}{|c|}{152} & 50 & 101 & 303 \\
$\begin{array}{l}\text { Age, yrs } \\
\text { Median (range) }\end{array}$ & $62(29-86)$ & $38(76 \%)$ & $64(63 \%)$ & $196(65 \%)$ \\
$\begin{array}{l}\text { BMI } \\
\text { Median (range) }\end{array}$ & $28(16-43)$ & $31(19-56)$ & $25(18-62)$ & $27(16-62)$ \\
$\begin{array}{l}\text { Hypertension } \\
\text { N (\%) } \\
\text { Diabetes }\end{array}$ & $74(49 \%)$ & $12(24 \%)$ & $19(19 \%)$ & $105(35 \%)$ \\
$\begin{array}{l}\text { N (\%) } \\
\text { Smokers } \\
\text { N (\%) }\end{array}$ & $19(13 \%)$ & $13(26 \%)$ & $9(9 \%)$ & $41(14 \%)$ \\
\hline
\end{tabular}

- Subjects: patients with clinical suspicion of Cushing's syndrome (CS), incidentaloma, and healthy controls

- Steroid assay: S-cortisol and s-DXT were assayed by liquid chromatography tandem mass spectrometry (LCMSMS)

- Evaluation: DST results were correlated to the final diagnosis based on current clinical guidelines

\section{Results}

- A s-DXT cut-off level at $3.3 \mathrm{nmol} / \mathrm{L}$ was chosen based on the $2.5 \%$ quantile of DXT in those suppressing s-cortisol $<50 \mathrm{nmol} / \mathrm{L}$ (fig.1)

- Applying this cut-off, 10/302 (3.3\%) DSTs were false positive with both inadequate s-DXT-levels and elevated s-cortisol, i.e., $12 \%$ of the positive DSTs could be explained by low levels of s- DXT (fig.2)

- Of these, three were misdiagnosed as subclinical-CS

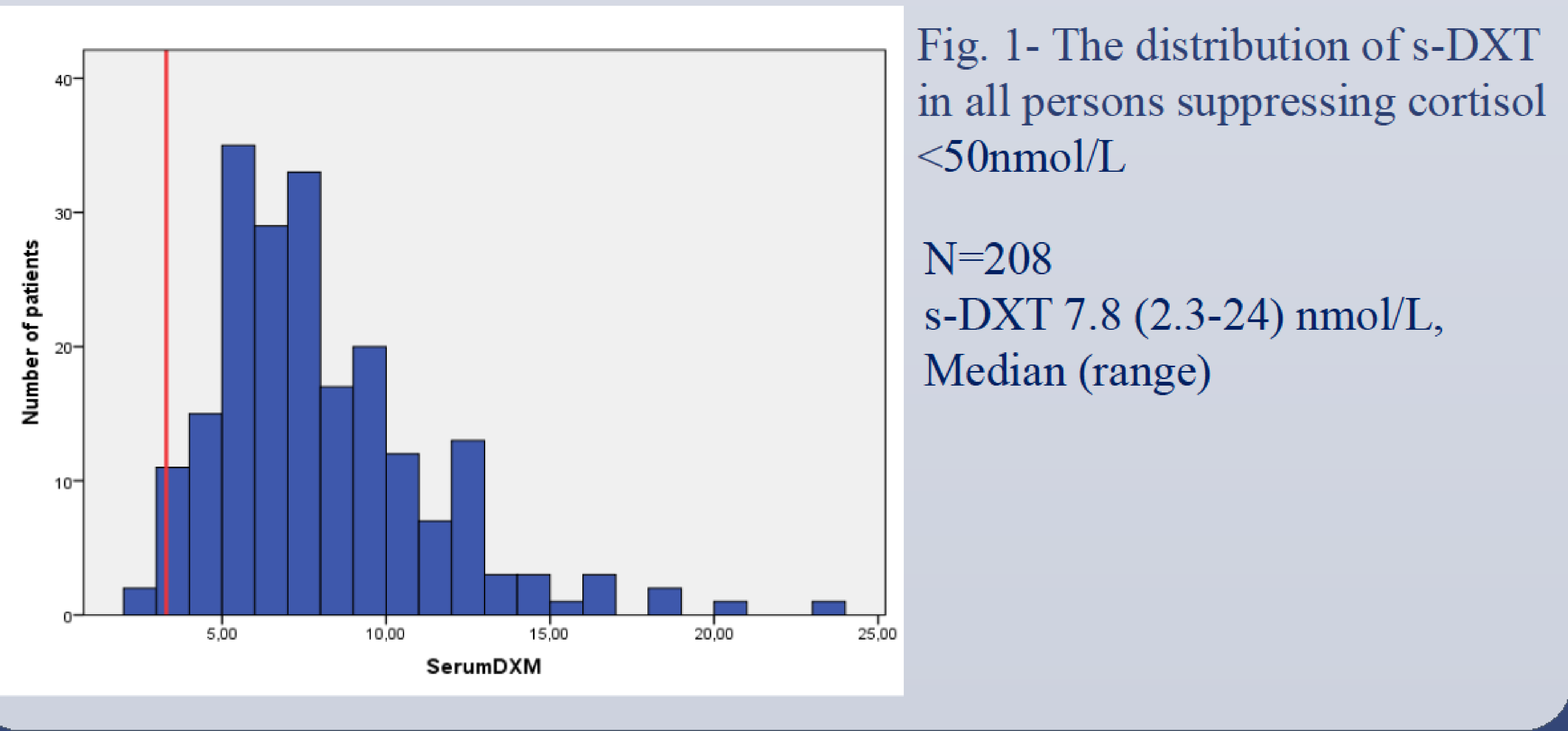

83/302 did not suppress s-cortisol ( $<50 \mathrm{nmol} / \mathrm{L})$. Of these 11 had overt $\mathrm{CS}$, and 27 subclinical CS (fig.2)

Fig. 2- Classification of positive DST results

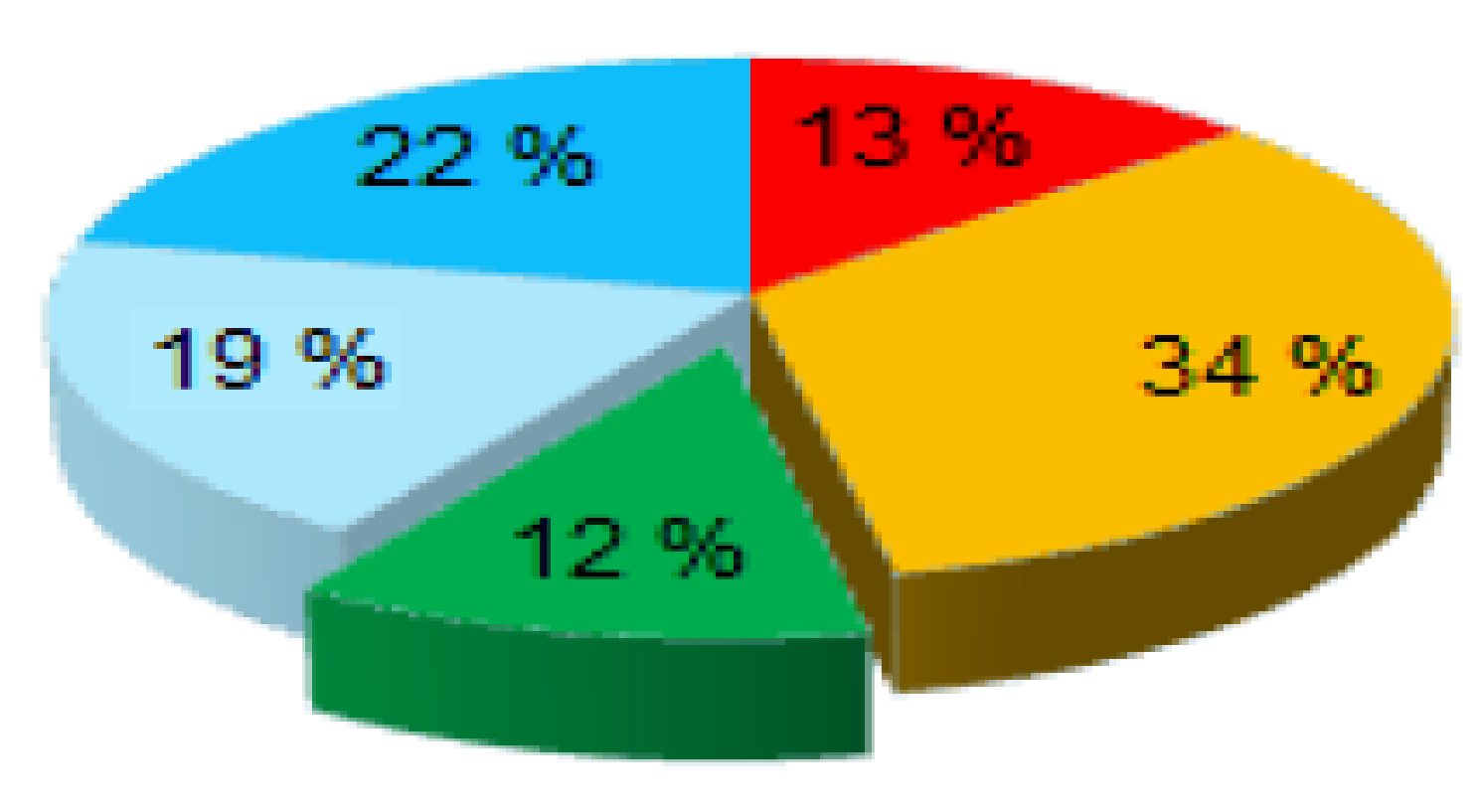

$$
\begin{aligned}
& \text { m Cushing's syndrome } \\
& \text { - Subclinical } \\
& \text { Cushing's syndrome } \\
& \text { m Low levels of S-DXT } \\
& \square \text { Oral Estrogens } \\
& =\text { Unknown }
\end{aligned}
$$

$N=83$

- Among non-CS samples, s-cortisol values were significantly $(\mathbf{p}<0.01)$ higher in the incidentaloma-group compared with the two other groups

Table 2. Post-DST s-cortisol and s-DXT in different subgroups of patients

\begin{tabular}{|l|r|r|r|}
\hline & Incidentalomas & \multicolumn{1}{|l|}{ Suspected CS } & \multicolumn{2}{l|}{$\begin{array}{l}\text { Healthy } \\
\text { controls }\end{array}$} \\
\hline $\begin{array}{l}\text { S-Cortisol (nmol/L) } \\
\text { Median (range) } \\
\begin{array}{l}\text { S-DXT (nmol/L) } \\
\text { Median (range) }\end{array}\end{array}$ & $42.6(13-577)$ & $22.7(9.9-289)$ & 22.2 (8.4-103) \\
\hline
\end{tabular}

- Inter-individul reproducibility of DST for s-cortisol is excellent (fig. 3)

Figure 3-Reproducibility of the DST

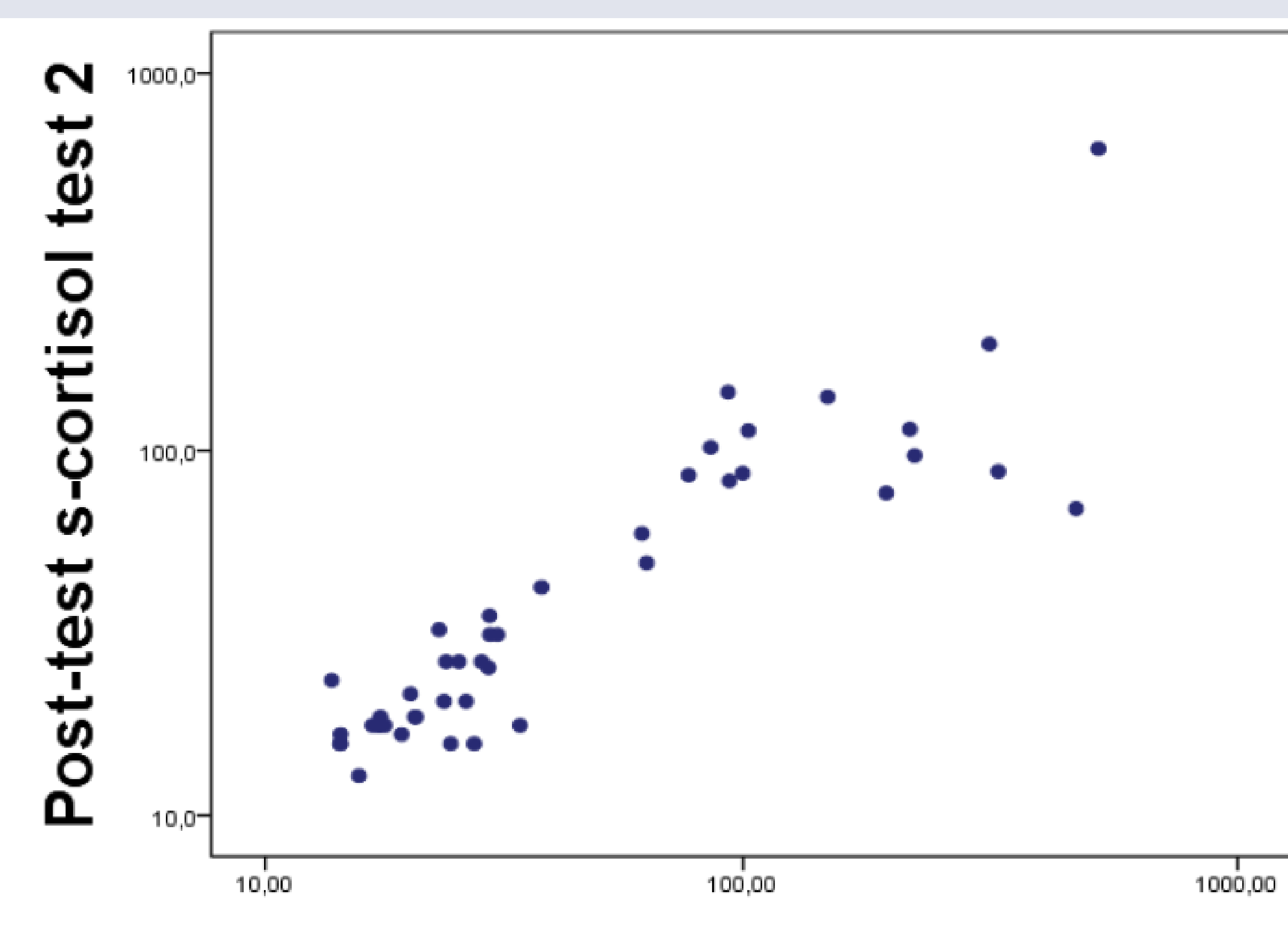

$\rho=0.87, P<0.01$

$\mathrm{N}=44$ (28 healthy controls, 16 patients)

Intra-class coefficient ICC $=0.94$

\section{Pst-test s-cortisol test 1}

\section{Conclusions}

A minimum s-DXT level of $3.3 \mathrm{nmol} / \mathrm{L}$ is needed to suppress s-cortisol $<$ $50 \mathrm{nmol} / \mathrm{L}$

- Simultaneous measurement of s-DXT and S-cortisol after DST increases the accuracy of the test, and reduces the risk of falsely diagnosing subclinical CS

- Abnormal absorption or metabolism of DXT is a common reason for false positive DSTs

- Post-test cortisol is significantly higher in incidentaloma patients compared with healthy controls and patients with suspected CS

- The reproducibility of DST is excellent

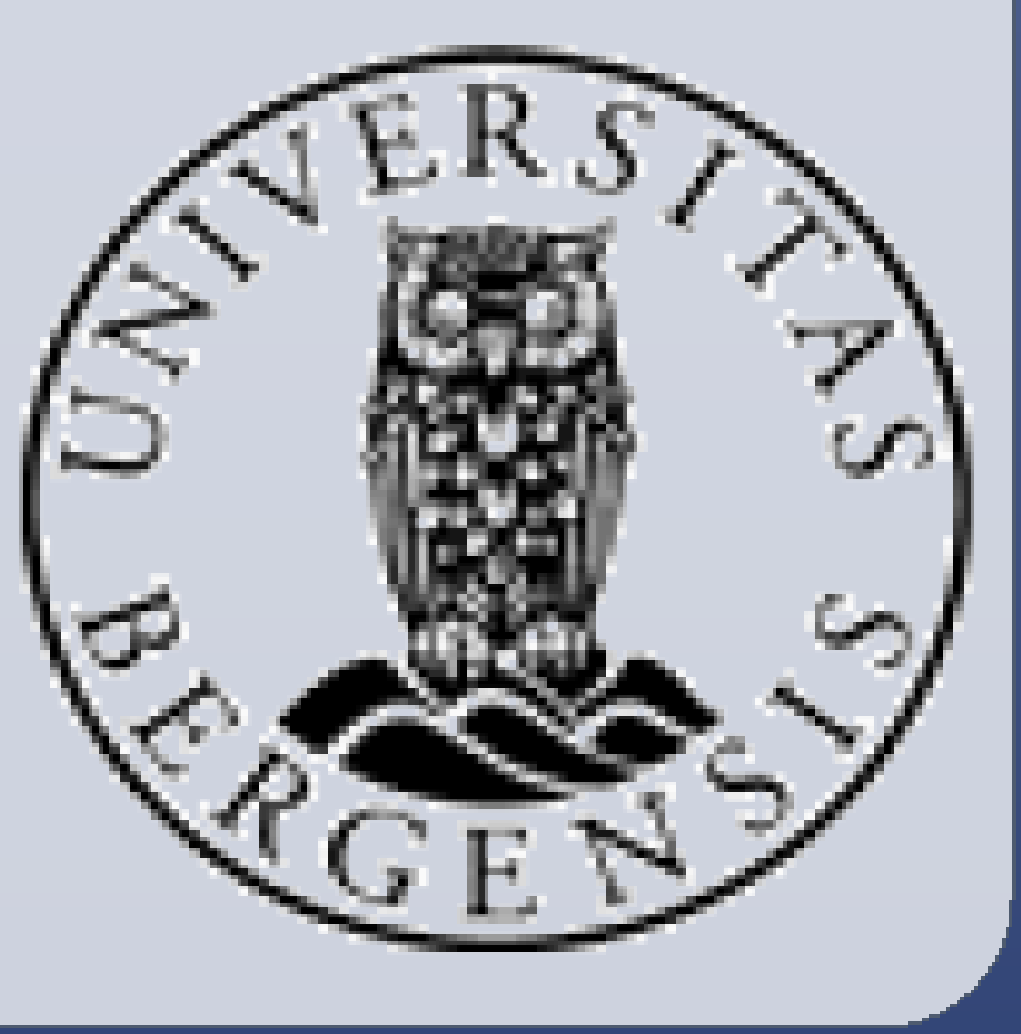

